\title{
A NEW METHOD OF DETERMINING VENOUS BLOOD-PRESSURE *
}

\author{
A. ALEXANDER HOWELL, M.D. \\ PHILADELPHA
}

A brief review of the work that has been done in devising methods for measuring venous blood-pressure will illustrate the general principles involved, and make easier the understanding of the new method to be described.

The veins of the hand and forearm have been those on which attention has been chiefly centered. With but two exceptions, the end sought has been a means of determining the pressure necessary to cause the collapse of one of these superficial veins. The observers have differed mainly, as will be noted, in the way in which this collapse was accomplished and the manner in which the required pressure was measured.

A contribution, dealing largely with the theoretical possibilities in the field of venous blood-pressures, was made by $\mathrm{Frey}^{1}$ in 1902. He went a step further, however, and presented an instrument for the determination of this pressure. The instrument, in brief, was so devised as to determine the weight in grams necessary to cause the collapse of a superficial vein. While simple and direct in principle it lost its practical value through technical difficulties as well as its failure to lend itself readily to the estimation of fluid pressures.

An advance on this empirical procedure was made by von Basch, ${ }^{2}$ who was the first to use air-pressure and thus to make possible the estimation directly in centimeters of water. The air-pressure was transmitted to the vein by holding over it a glass cylinder, which was in turn connected with a water manometer. In this way the pressure necessary to cause the collapse of the vein was measured.

The evident fault here was a variable in the force with which the cylinder was held against the skin, a considerable factor when dealing with pressures so low as venous ones are known to be. Although again satisfactory results were not forthcoming, the method of approaching the problem was new and opened the way for further development of the same idea, by von Recklinghausen and later by Eyster and Hooker.

The elimination of the glass cylinder from the procedure was the

*From the Medical Dispensary of the University Hospital.

1. Frey, A.: Deutsch. Arch. f. klin. Med., 1902, Ixxiii, 511.

2. von Basch, S.: Wien. med. Presse, 1904, No. 20, p. 962; Arch. d. sc. biol., 1904, Supp. xi, 117. 
advance made by von Recklinghausen. ${ }^{3}$ He substituted what practically arnounted to a rubber cylinder for the glass cylinder of von Basch. This was made by cutting openings in the top and bottom of a circular rubber bag. The lower opening was placed on the vein, while the upper was closed by a glass plate. Air was admitted through an opening in the side and the collapse of the vein was viewed through the glass. The pressure required was measured on a water manometer. Air-tightness was obtained by covering the skin and the surface of the rubber in contact with the glass with glycerin.

The next advance was again along mechanical lines and came with the introduction of the box-frame by Eyster and Hooker. ${ }^{4}$ This appliance supplanted the glass and rubber cylinders. The frame was closed below by a rubber dam, in which an opening was cut, and above by a glass plate. In using the apparatus the opening in the rubber dam was placed over a vein, and as the pressure within the box was raised, the collapse of the vein was viewed from above, through the glass. The box was held in place by tapes passing around the arm and thus left both hands of the operator free. Measurements were in centimeters of water.

Oliver $^{5}$ and Sewall ${ }^{6}$ independently followed out the problem in a different direction. While bringing pressure to bear on the superficial veins, they did this through the medium of a spring which had been standardized against mercury. They hardly seem to have opened as promising a field as the other observers, the difficulties usually associated with spring devices suggesting themselves.

One of the earliest methods, that of Gaertner, ${ }^{7}$ while simplicity itself and useful in many instances, has obvious limitations. It consists in raising the arm slowly until the veins on the back of the hand disappear, the height above the heart at which this occurs giving the venous pressure.

A method which leaves little to be desired from a scientific standpoint has been described by Moritz and von Tabora. ${ }^{8}$ Its chief value is in the directness of application. The pressure in the median vein is measured by passing a cannula into this vessel. The procedure is not unlike the administration of an intravenous injection. The pressure in the vein is determined by noting the point below which a column of solution: in communication with the vein, will not fall. In other words, the pressure, which is just insufficient to cause a further passage of fluid from the manometer into the vein, is read; as the fluids within the vein and the

3. von Recklinghausen: Arch. f. exper. Path. u. Pharmakol., lv, 463.

4. Eyster and Hooker: Johns Hopkins Hosp. Bull., September, 1908, xix, 274.

5. Oliver, G.: Jour. Physiol., 1898, xxii, p. xli; 1899, xxiii, p. v. Jour. Balneol. and Climat., October, 1903.

6. Sewall, H.: Jour. Am. Med. Assn., 1906, xlvii, 1279.

7. Gaertner, G.: München. med. Wchnschr., 1904, lxxiv, 2038.

8. Moritz and v. Tabora: Deutsch. Arch. f. klin. Med., 1909-1910, xeviii, 475. 
manometer are in equilibrium at this point, this reading is of course the venous pressure.

The scope of such a method must of necessity be limited and will lie chiefly in hospital practice, where patients are well under control and where the aseptic measures employed are above suspicion. Moritz and von Tabora examined a large number of cases in this way and feel no fear as to untoward results from the procedure.

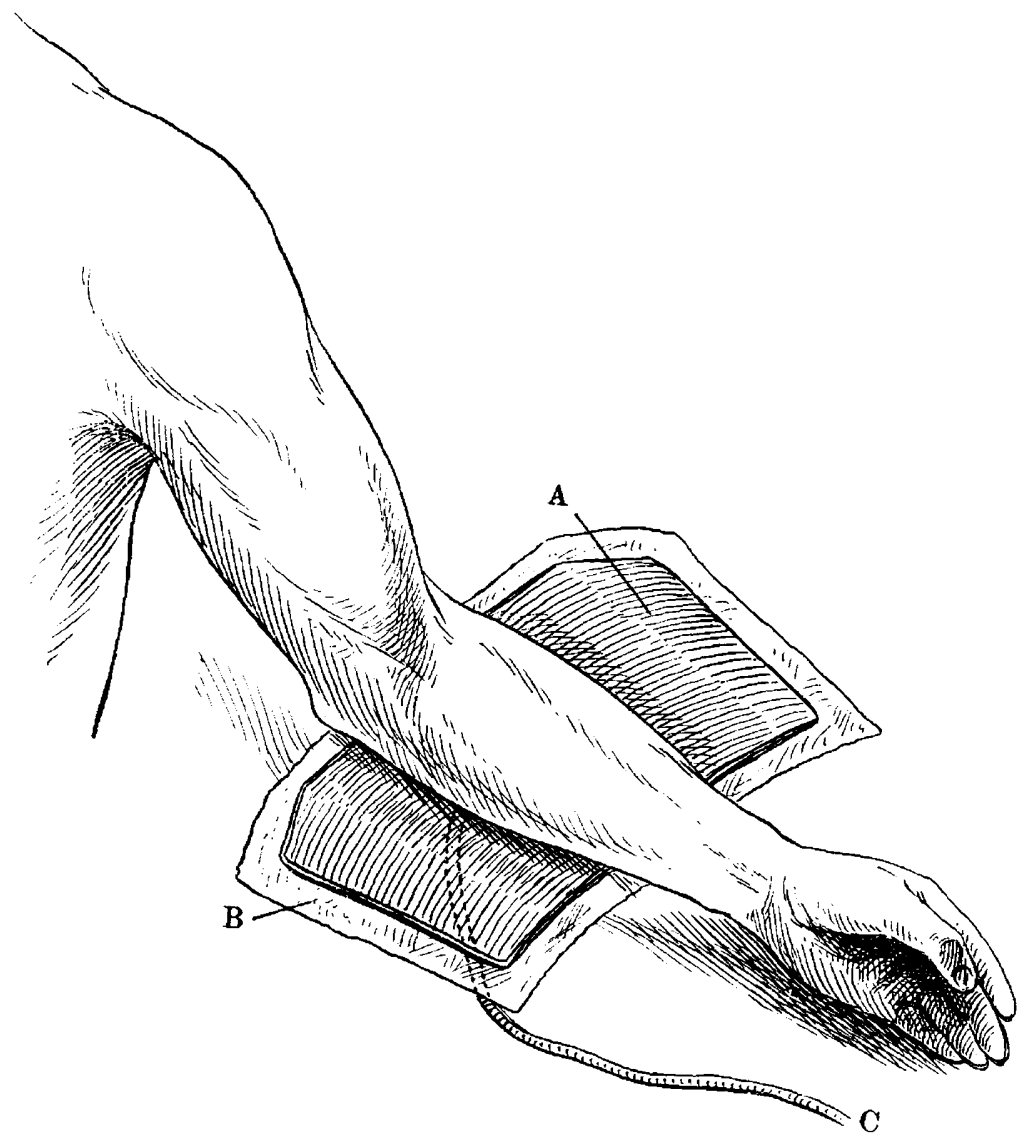

Fig. 1,-Lower cuff (rubber bag and eovering) before being wrapped around arm. A, rubber bag, made of light rubber dam, so shaped that when wrapped around the forearm with its covering $B$, fits as shown in Figure 2. B, inelastic covering of light material, holding $A$ in place. C, rubber tube admitting air to rubber bag $\mathrm{A}$, passing through covering $\mathrm{B}$, as shown at $\mathrm{H}$, Figure 2 .

As a check to the accuracy of other methods this is the one to be used.

To one who interests himself at all in observing the superficial veins it soon becomes evident in what a variable quantity he is dealing. The thickness of the skin. the amount of subcutaneous tissue and the varying structure of the veins themselres, make a large percentage of individuals 
poor subjects for study by any of the above means, except the last described.

A procedure which would be less dependent on these variables and render observation possible on all or nearly all of the veins of a part at once, was the leading thought in the search for a new method. The congestion and swelling of the arm, distal to the cuff, as the pressure is dropped below the maximum arterial pressure, in making an ordinary blood-pressure reading, suggested the possibility of utilizing this phenomenon in such a way as to determine the venous pressure. The congestion and increase in volume of the arm, below the cuff, being due to the

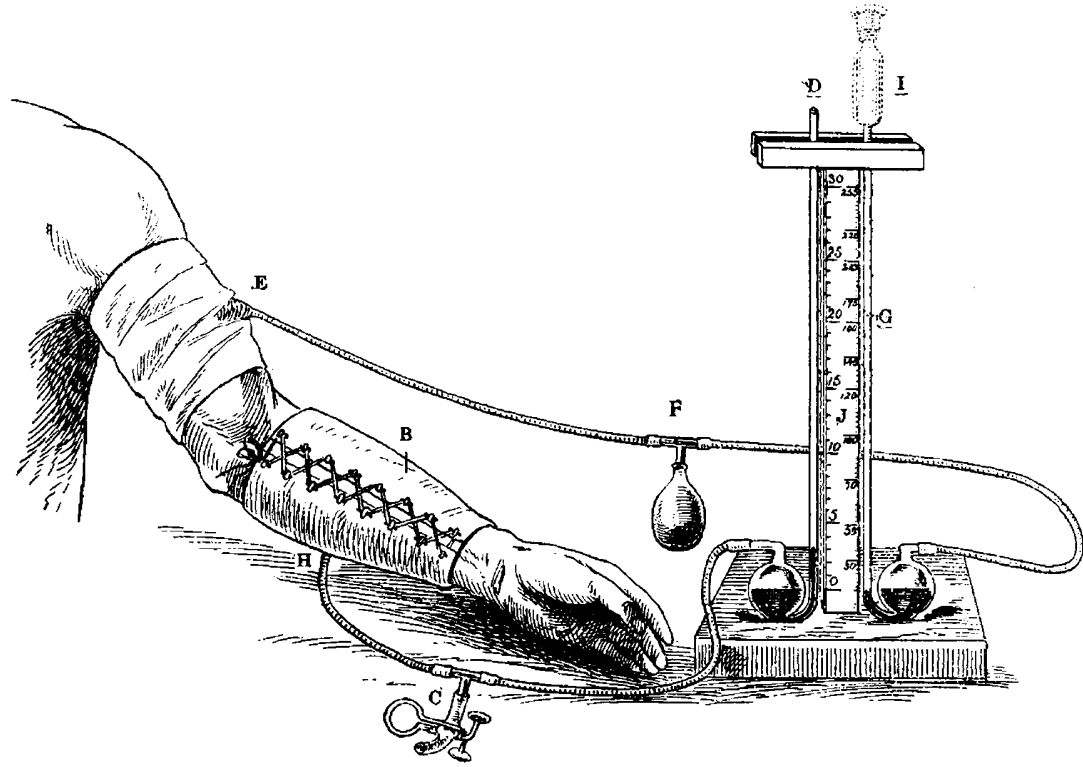

Fig. 2.-Upper and lower cuffs applied and attached to their respective water columns. E, light cuff for constricting upper arm and obstructing venous return. $F$, glass $T$ and bulb, by means of which pressure is raised in $E$. G, water column measuring pressure in $\mathbf{E}$. $\mathbf{B}$, inelastic covering of light material encircling rubber bag. $C$, glass $T$, side tube and clip, by means of which pressure can be raised in A, Figure 1. D, water column measuring pressure in A. (Fig. 1).

obstruction of the venous return, while the arterial flow was still in progress, it was obvious that if it were possible to determine the pressure at which this venous obstruction first took place - this would be the venous pressure.

A means of constricting the arm, and thus obstructing the venous return, was secured by modifying slightly the usual sphygmomanometer cuff. The change consisted in using a lighter rubber bag which was held in place by a few turns of muslin bandage lightly applied. The lighter materials are used as they transmit more accurately and quickly the low pressures used in making an observation of this kind. 
A way to determine the first increase in the volume of the forearm was the real problem to be solved. This has been done by devising a special cuff, similar in general to the cuff of the arterial sphygmomanometer, but differing in that it is patterned to fit the tapering forearm and in that it is made of light rubber dam with a light inelastic covering, as diagrammatically represented in Figures 1 and 2 .

As the arm is constricted at $\mathrm{E}$, by raising the pressure in $\mathrm{E} \mathrm{F} \mathrm{G}$ (Fig. 2), a point is reached where the pressure within the cuff just equals and then slightly exceeds that within the veins. When this point is reached the veins will collapse and a damming back of the venous blood occurs. This manifests itself in an engorgement of the veins below the point of constriction. This increase in the volume of the veins, and of the forearm as a whole, is recorded by the system B C D (Fig. 2) as follows:

Prior to bringing any constricting force to bear at $\mathrm{E}$, a pressure of $3 \mathrm{~cm}$. of water is developed in the system B C D (Fig. 2) by gently blowing in by mouth at $\mathrm{C}$, until the water column registers the desired pressure. The pressure of $3 \mathrm{~cm}$. has been arbitrarily chosen, for the inflation of A (Fig. 1), as being sufficiently high to overcome the inherent resistance of the cuff to inflation and yet below the probable venous pressure. As swelling of the veins in the forearm occurs, following constriction at $\mathrm{E}$, room is made for this increase of volume, within the inelastic covering B (Fig. 2), by displacement of a corresponding amount of air from the contained rubber bag A (Fig. 1). As this displacement necessitates an increased pressure in the closed system B C D (Fig. 2), this increase is registered in the column of water at D. The rest of the observation consists in noting the pressure required in the system E F G (Fig. 2) to cause this first rise in the water column at D.

Directions then for applying and using the apparatus are as follows:

1. Apply the special cuff to the forearm, first removing the clip at C, so that all air is forced out of A (Fig. 1) when the cuff is laced in place.

2. Blow in at $\mathrm{C}$ until $\mathrm{A}$ (Fig. 1) is well filled; readjust the clip at $\mathrm{C}$ and let the air slowly escape until the water column D registers $3 \mathrm{~cm}$.

3. Apply the upper cuff E, lightly.

4. By means of the bulb at $F$, bring the constricting force to bear at $\mathrm{E}$, by raising the pressure in $\mathrm{E} \mathrm{F} \mathrm{G}$.

5. Note on the scale to the left of $J$, the pressure in centimeters of water necessary in $\mathrm{E} \mathrm{F} \mathrm{G} \mathrm{(Fig.} \mathrm{2)} \mathrm{to} \mathrm{cause} \mathrm{the} \mathrm{first} \mathrm{rise} \mathrm{in} \mathrm{column} \mathrm{D.}$ This will be the desired venous pressure.

With the expectation of learning something of venous fulness and tone, the pressure has still further been raised in E F G (Fig. 2) and 
the extent of the rise in column D (Fig. 2) noted. Rises occurring in column D, under similar pressures in column $\mathrm{G}$, have then been compared.

In making a venous blood-pressure estimation, it is necessary, as has been realized by all the workers in this field, to have the vein or veins under observation, at the level of the heart. If this is impossible it is then necessary to correct the reading for the force of gravity thus brought into play. Levels above the heart decrease and those below the heart correspondingly increase the reading. The venous blood-pressure, for example, in the forearm or hand hanging at the side is greater than it would be when the forearm or hand is placed at the level of the heart. The costal angle, as suggested by von Recklinghausen, has been the point chosen as marking the heart level. This landmark is especially appropriate as it localizes the right heart, which is such an important factor in the maintenance of venous blood-pressure.

With this instrument the venous blood-pressure has always been taken in conjunction with the arterial pressure. This has been made possible without changing to the usual sphygmomanometer by utilizing the "airwater sphygmomanometer," as described by Bendick. ${ }^{9}$ This consists in closing the upper end of the column $G$, by screwing down the cap, and raising the water column against the pressure of the enclosed air in the bulb I (Fig. 2). In taking the arterial pressure the systolic and diastolic pressures and the auscultatory sequences ${ }^{10}$ have been recorded. The venous pressure should always be taken before the arterial, as the latter overdistends the veins and renders observations on them, in this condition, undesirable.

It is interesting here to note how susceptible the veins are to external stimuli, especially, as has been pointed out by others, to cold and friction. As an estimation on the same individual on a warm and a cold day presents differences, it has been found necessary to note the day as warm. cool or cold. The readings being also influenced by the size of the arm, the thickness of the skin and the prominence or obscurity of the superficial veins, these facts have been noted. In this way it is possible to class individuals in more or less fixed groups presenting similarities in their readings.

In the examination by this new method of a series of cases, which could be looked on as normal from a cardiovascular standpoint, the average venous pressure was found to be $7.6 \mathrm{~cm}$. of water. In this series, the lowest pressure recorded was $4 \mathrm{~cm}$., and the highest $13 \mathrm{~cm}$. In the case of the lower reading the patient was a young man with a tentative diagnosis of incipient tuberculosis. He had rather a small arm, with

9. Bendick, A. J.: Jour. Am. Med. Assn., June 24, 1911, p. 1873.

10. Goodman and Howell: University Med. Bull., November, 1910, p. 469. Am. Jour. Med. Sc., September, 1911. 
soft moist skin, little subcutaneous tissue and prominent veins; that is, he was an extremely favorable subject for examination by this method. The patient showing the higher reading was a man of 48 years, with a large arm, thick skin, firm subcutaneous tissue and superficial veins which were hardly visible, an individual presenting conditions which would obviously raise the reading. These two cases illustrate what was referred to above, in speaking of the necessity of grouping cases in classes which would present similarities in their readings. In the case of the young man the actual pressure within the veins was closely approximated, while in that of the older man the reading was undoubtedly too high. Since, however, the error is constant for individuals presenting the same physical conditions, allowance can be made for this.

An average has also been taken in a group of cases which showed circulatory disturbance, varying from those of lesser degree to advanced cases in which marked decompensation was present. The average venous pressure in this series was $13.9 \mathrm{~cm}$. of water. The lowest reading of the series was met in a case of well-compensated mitral regurgitation and was $7 \mathrm{~cm}$. The highest was $25.0 \mathrm{~cm}$., in a case of interstitial nephritis showing very high blood-pressure and the signs of chronic uremia. Comparing these results with those of Moritz and von Tabora, obtained by the use of their direct method, it is found that our figures are too high. These observers found the average venous pressure in normal individuals to be $5.2 \mathrm{~cm}$. of water. The lowest reading in their series was $1.1 \mathrm{~cm}$, and the highest $8.7 \mathrm{~cm}$, the former in a case of wellcompensated myocarditis and the latter in a patient convalescent from pneumonia.

This comparison shows the average obtained by the new method to be $2.4 \mathrm{~cm}$. higher than it should be. It is evident also that the error is less in the case of the young man who presented favorable circumstances, than in the older one in whom modifying conditions existed.

As one of the chief aids to be derived from the estimation of venous blood-pressures will doubtless be in the following of cases as the patients improve or grow worse, the difficulty under such conditions associated with the correction of readings will be largely eliminated.

1416 South Fifty-Eighth Street. 